\title{
Kristalinitas Abu Vulkanik Gunung Soputan dan Implikasinya Terhadap Perilaku Eksplosif pada Erupsi Tahun 2016 dan 2018
}

\author{
Maria D. Bobanto ${ }^{1)}$, Ferdy Ferdy ${ }^{1)}$, Guntur Pasau ${ }^{1)}$, D.D. Tampemawas ${ }^{1)}$, A. Saefuloh ${ }^{2)}$, \\ Dolfie P. Pandara ${ }^{1^{*}}$ \\ ${ }^{1)} J u r u s a n$ Fisika Fakultas Matematika dan Ilmu Pengetahuan Alam, \\ Universitas Sam Ratulangi, Manado, Indonesia \\ 2) Pos Pengamatan Gunung Soputan, PVMBG Badan Geologi, KESDM, Manado, Indonesia \\ *Corresponding Author: dpandara_fisika@unsrat.ac.id
}

\begin{abstract}
ABSTRAK
Gunung Soputan adalah gunung basaltik dengan tipe erupsi eksplosif. Tipikal eksplosif berkaitan dengan karakter magma. Penelitian ini bertujuan untuk mengkaji kristalinitas abu vulkanik Gunung Soputan tahun 2016 dan 2018 dan implikasinya terhadap perilaku eksplosifnya. Kristalinitas abu vulkanik dikarakterisasi menggunakan peralatan difraktometer sinar X. Indeks kristalinitas dikalkulasi menggunakan persamaan Soltys dan ukuran kristal dikomputasi dengan persamaan Debye-Scherrer. Morfologi partikel abu dikarakterisasi menggunakan SEM. Hasil karakterisasi menunjukkan bahwa abu Soputan tahun 2016 dan 2018 memiliki indeks kristalinitas yang tinggi dan mengandung sejumlah kristal berukuran kecil serta memiliki dua bentuk morfologi yaitu bentuk padat dan blok bervesikular untuk abu hasil erupsi 4 Januari 2016, dan bentuk padat dan blok untuk abu hasil erupsi 6 Februari 2016 dan 3 Oktober 2018. Kristalinitas yang tinggi menyebabkan magma Soputan memiliki viskositas yang memadai untuk terjadinya erupsi yang eksplosif. Karakter eksplosif Gunung Soputan terekam dalam morfologi abu vulkaniknya.
\end{abstract}

Kata kunci: Abu vulkanik; erupsi eksplosif; fragmentasi getas; gunung Soputan; indeks kristalinitas

\section{Cristallinity of Volcanic Ash of Mount Soputan and Its Implication to Explosive Behaviour on Eruption of 2016 and 2018}

\begin{abstract}
Mount Soputan is a basaltic mountain with an explosive eruption type. Typical explosives relate to the character of the magma. This study aims to examine the crystallinity of Mount Soputan's volcanic ash in 2016 and 2018 and its implications for its explosive behavior. The crystallinity of volcanic ash was characterized using an X-ray diffractometer. The crystallinity index was calculated using the Soltys equation and the crystal size computed using the Debye-Scherrer equation. The morphology of the ash particles was characterized using SEM. The characterization results show that the 2016 and 2018 Soputan ash has a high crystallinity index and contains a number of small crystals and has two morphological forms, namely solid form and vesicular block for ash from the eruption on January 4, 2016, and solid and block form for eruption ash 6 February 2016 and October 3 2018. High crystallinity causes the Soputan magma to have sufficient viscosity for explosive eruptions. The explosive character of Mount Soputan is recorded in the morphology of its volcanic ash.
\end{abstract}

Keywords: Brittle fragmentation; crystallinity index; explosive eruption; mount Soputan; volcanic ash

(Article History: Received 18-11-2020; Accepted 27-03-2021; Published 13-04-2021)

\section{PENDAHULUAN}

Gunung Soputan adalah salah satu gunung berapi basaltik yang sangat aktif di Indonesia dan merupakan bagian dari kompleks vulkanik Sempu-Soputan yang terletak di selatan Kaldera Tondano dan busur Sangihe $\left(1^{\circ} 6.90^{\prime} \mathrm{N}\right.$ dan $\left.124^{\circ} 44.2^{\prime} \mathrm{E}\right)$ (Pallister et al., 2012). Erupsi Gunung Soputan umumnya dapat berupa erupsi eksplosif dengan ketinggian kolom abu mencapai $13 \mathrm{~km}$ dengan Indeks Eksplosivitas Vulkanik (IEV) sekitar 2-4 dan pembentukan kubah lava efusif serta dapat disertai aliran piroklastik dengan jangkauan mencapai 5,5 km (Kunrat, 2017). 
Tipikal eksplosif bagi gunung api dengan komposisi magma basaltik seperti Gunung Soputan merupakan sesuatu yang tidak umum terjadi. Magma basaltik merupakan tipikal magma dengan kandungan silika rendah, viskositas rendah dan kandungan gas juga rendah sehingga tipikal erupsinya bersifat lemah. Analisis terhadap material piroklastik berupa batuan dan abu vulkanik yang disemburkan Gunung Soputan pada periode 2003-2011 (Pallister et al., 2012) dan 2015 (Kunrat, 2017) menunjukkan bahwa magma Soputan bersifat basaltik dan erupsinya bertipikal eksplosif. Eksplosivitas erupsi Gunung Soputan tahun 2015 berlanjut pada tahun 2016 dan 2018. Eksplosivitas erupsi tersebut urgen untuk terus dipelajari karena aspek bahaya seperti terjadinya aliran piroklastik (Iacuaniello et al., 2020) dan sebaran abu halus (Tomašek et al., 2019).

Kristalisasi merupakan salah satu prekursor bagi perilaku eksplosif suatu gunung api (Moitra et al., 2018). Hasil analisis terhadap abu Soputan dari erupsi eksplosif tahun 2015 menunjukkan bahwa letusan eksplosif diawali dengan pengisian ulang magma kaya volatil pada suatu kantung dalam kemudian bertransformasi menjadi magma yang lebih kaya kristal dan gas pada suatu tingkat yang lebih dangkal (Kunrat, 2017). Studi tersebut berfokus pada analisis kandungan mineral baik fenokris maupun mikrolit, komposisi senyawa utama dan keberadaan unsur tanah jarang untuk memahami sistem magmatik dan sifat eksplosif Gunung Soputan. Proses kristalisasi diamati dari aspek kelimpahan mineral plagioklase dibandingkan dengan kandungan olivin. Pada riset ini, aspek kristalinitas dikaji dengan pendekatan yang lebih sederhana menggunakan hasil karakterisasi difraksi sinar-X (XRD) dan berfokus pada indeks kristalinitas dan ukuran kristal yang terkandung di dalam abu Soputan tahun 2016 dan 2018. Kajian terhadap hasil XRD akan dikonfirmasi menggunakan hasil foto SEM (Scanning electron microscopy) dan data visual saat terjadinya erupsi. Kajian terhadap kristalinitas abu vulkanik Gunung Soputan dan implikasinya terhadap perilaku eksplosif pada erupsi tahun 2016 dan 2018 merupakan tujuan yang akan dicapai melalui penelitian ini.

\section{METODE PENELITIAN}

Penelitian ini dilakukan di Laboratorium Geofisika Unsrat dalam interval waktu Agustus-Oktober 2020. Bahan penelitian ini berupa abu vulkanik segar dari letusan Gunung Soputan tahun 2016 dan 2018. Abu letusan tahun 2016 di ambil di desa Raringis yang berada $8 \mathrm{~km}$ di sebelah Timur dan abu letusan tahun 2018 diambil di desa Tolombukan yang terletak $11 \mathrm{~km}$ di selatan Gunung Soputan. Sampel abu adalah abu jatuhan dari letusan tanggal 4 Januari 2016, 6 Februari 2016 dan 3 Oktober 2018. Partikel abu kemudian dipisahkan menjadi tiga fraksi yaitu fraksi kasar (> $125 \mu \mathrm{m})$, sedang (125-70 $\mu \mathrm{m})$, dan halus $(<70 \mu \mathrm{m})$. Selanjutnya, karakterisasi abu dilakukan dengan menggunakan peralatan XRD dan SEM yang ada di Laboratorium Mineral dan Material Maju Universitas Negeri Malang.

Fraksi abu kasar dikarakterisasi menggunakan diffraktometer bertipe Xpert-Pro dengan sinar-X target $\mathrm{CuK} \alpha$ $1,54060 \AA$ Å, tegangan generator $40 \mathrm{kV}$ dan arus $35 \mathrm{~mA}$. Pengukuran XRD dilakukan pada kecepatan $0,02^{\circ}$ per menit dari sudut $10,01^{\circ}$ hingga $89,99^{\circ}$. Berdasarkan data sudut 2 theta dan intensitas dari spektral XRD dikalkulasi ukuran kristal dan indeks kristalinitas.

Perhitungan diameter kristal menggunakan persamaan Debye-Scherer yaitu:

$$
D=\frac{0,9 \lambda}{B \cos \theta}
$$

di mana $\mathrm{D}$ adalah diameter partikel $(\mathrm{nm}), \lambda$ adalah panjang gelombang sinar X $(\mathrm{nm}), \mathrm{B}$ adalah FWHM (full width half maximum) dari pita difraksi (radian), dan $\theta$ adalah sudut difraksi Bragg (radian) (Hargreaves, 2016).

Perhitungan indeks kristalinitas menggunakan persamaan Soltys yaitu:

$$
\mathrm{CI}=(\mathrm{CA} / \mathrm{TA}) * 100 \%
$$

di mana CA adalah luas semua daerah kristal dan TA adalah luas daerah total baik fase kristal maupun amorf (Pan et al., 2016). Perhitungan luas daerah kristal dan amorf, dan FWHM dari puncak spektra XRD dilakukan menggunakan perangkat lunak Origin Pro 8.5, sedangkan kalkulasi diameter kristal dan indeks kristalinitas menggunakan Microsoft Excell. Karakterisasi SEM dilakukan pada fraksi abu medium dan kasar. Ada tidaknya vesikel sebagai jejak gelembung gas, aspek 
kepadatan partikel dan bentuk geometri dari abu vulkanik diinvestigasi menggunakan SEM Merk FEI bertipe Inspect-S50.

\section{HASIL DAN PEMBAHASAN}

Difraktogram sinar $\mathrm{X}$ untuk ketiga sampel abu ditunjukkan pada Gambar 1 . Terdapat 12 puncak-puncak spektral XRD dari ketiga sampel abu berkaitan dengan sudut 2-theta sebesar 21,90;22,70;23,60;24,40; 26,$40 ; 27,90$ (intensitas tertinggi); 29,60; 30,$30 ; 31,50 ; 33,80 ; \quad 35,50$ dan 42,20 . Meskipun ada perbedaan dalam kristalinitas dan ukuran kristal, karakter kristalografi ketiga sampel memiliki struktur yang sama.

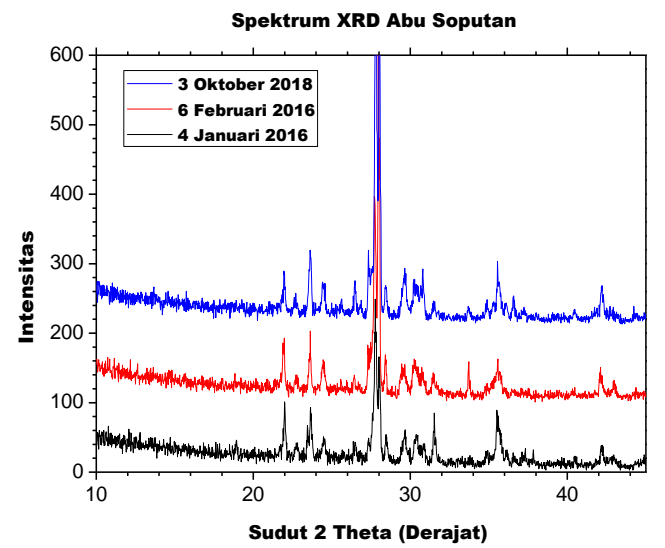

Gambar 1. Spektrum XRD dari Abu Soputan Tahun 2016 dan 2018 (Fraksi kasar)

Berdasarkan persamaan DebyeScherer, ukuran kristal berbanding terbalik dengan nilai FWHM (Hargreaves, 2016). Intensitas yang rendah dari puncak difraksi sinar $\mathrm{X}$ atau bidang kristal menghasilkan nilai FWHM yang besar. Intensitas XRD yang rendah menunjukkan bahwa kristal yang terbentuk dalam material abu berukuran kecil. Karakteristik spektral XRD memperlihatkan bahwa massa dasar abu Soputan merupakan campuran mikrolit dan poliamorf kristalin kaca (Pandara, 2017)

Ukuran kristal dalam sampel abu Soputan bervariasi dengan diameter rata-rata partikel abu berturut-turut adalah $39,1 \mathrm{~nm}$ untuk erupsi 4 Januari 2016, $42,4 \mathrm{~nm}$ untuk erupsi 6 Februari 2016, dan 43,7 nm untuk erupsi 3 Oktober 2018 seperti ditunjukkan pada Gambar 2. Variasi ukuran ini menunjukkan bahwa kristal dalam magma Soputan merupakan mikrolit. Dimensi kristal tersebut mendukung fakta bahwa abu vulkanik
Soputan merupakan abu halus yang berkorelasi dengan erupsi basaltik eksplosif (Tomašek et al., 2019)

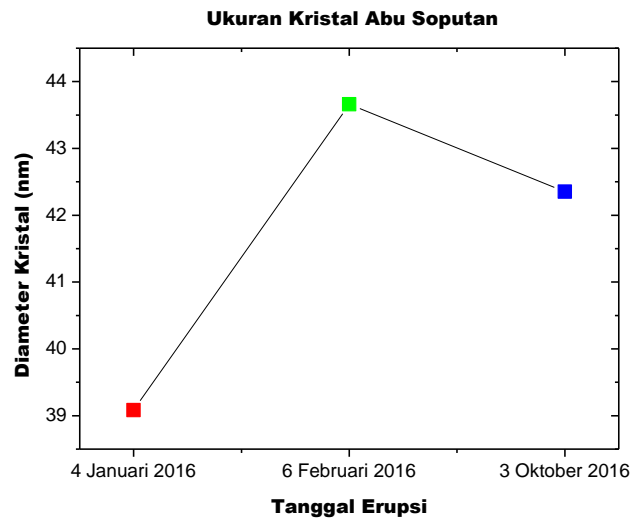

Gambar 2. Variasi Ukuran Kristal dalam Abu Soputan Tahun 2016 dan 2018

Hasil perhitungan indeks kristalinitas menunjukkan bahwa ketiga sampel abu memiliki kristalinitas yang tinggi seperti tampak pada Gambar 3. Indeks kristalinitas dari abu Soputan bernilai di atas 50\% yang menyatakan bahwa magma Soputan adalah magma yang kaya kristal. Variasi indeks kristalinitas menunjukkan adanya proses kristalisasi sebelum terjadinya ketiga erupsi. Adanya proses kristalisasi diindikasikan pula oleh variasi ukuran kristal yang terbentuk pada setiap erupsi.

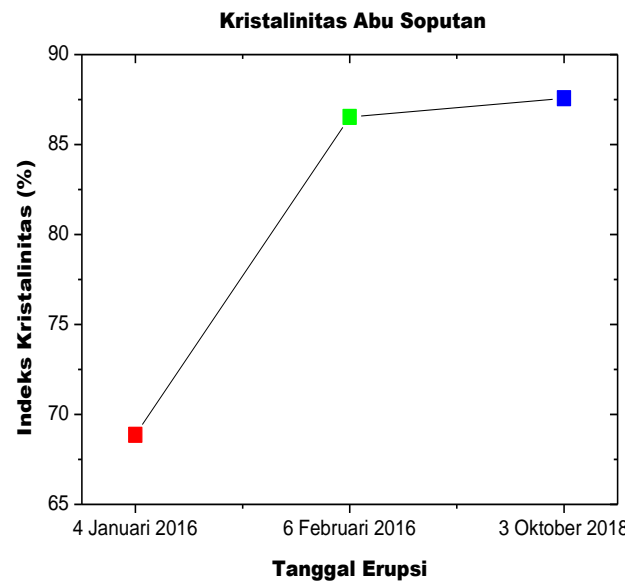

Gambar 3. Indeks Kristalinitas Abu Soputan Tahun 2016 dan 2018

Indeks kristalinitas yang tinggi berkaitan dengan besarnya kandungan fraksi kristal di dalam magma. Fraksi kristal dalam magma akan meningkatkan viskositas magma yang dapat menghambat pertumbuhan gelembung gas dan memicu fragmentasi (Namiki \& Manga, 2008). 
Gambar 4 memperlihatkan perbedaan fraksi kristal dalam magma dari letusan 4 Januari 2016 dibandingkan dengan magma dari letusan 6 Februari 2016 dan letusan 3 Oktober 2018 yang tampak pada jejak vesikel dalam foto SEM. Peningkatan indeks kristalinitas berkorelasi dengan kandungan vesikel dalam foto SEM. Partikel abu dari letusan 4 Januari 2016 memiliki bentuk padat dan blok bervesikular, sedangkan partikel abu dari letusan 6 Februari 2016 dan letusan 3 Oktober 2018 berbentuk padat dan blok.

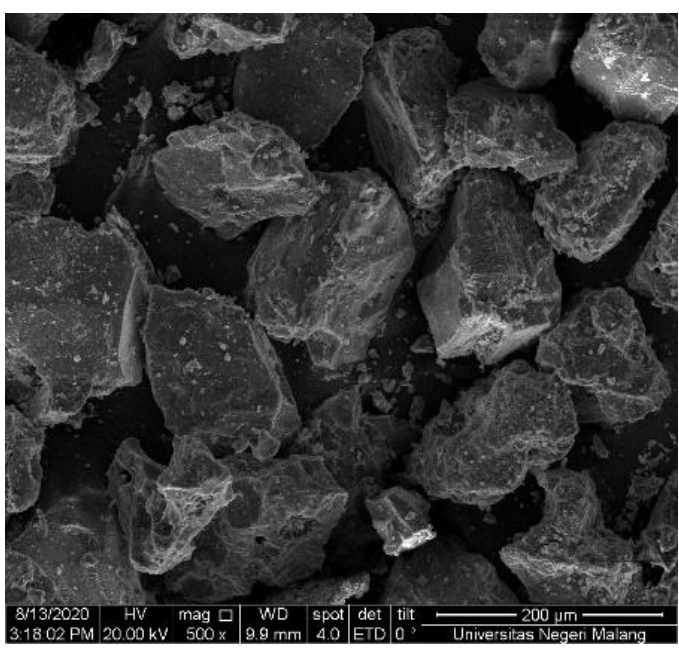

a. $\quad$ Abu letusan 4 Januari 2016

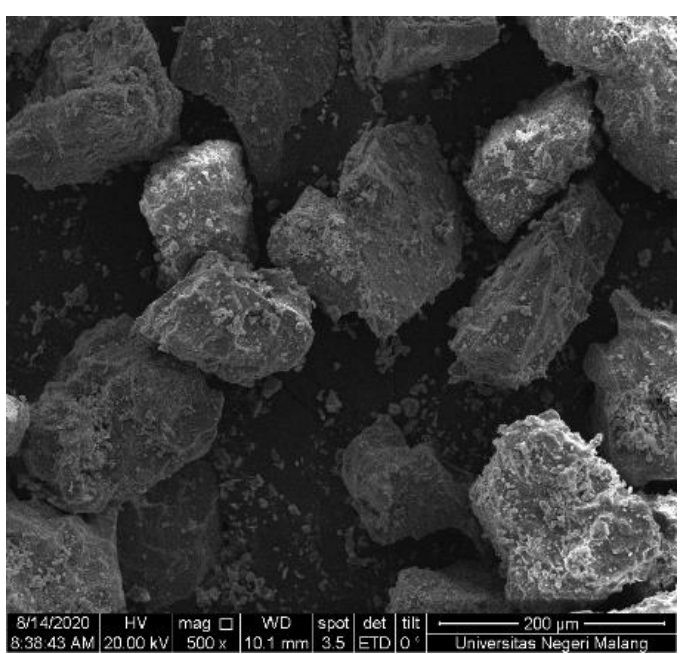

b. Abu letusan 6 Februari 2016

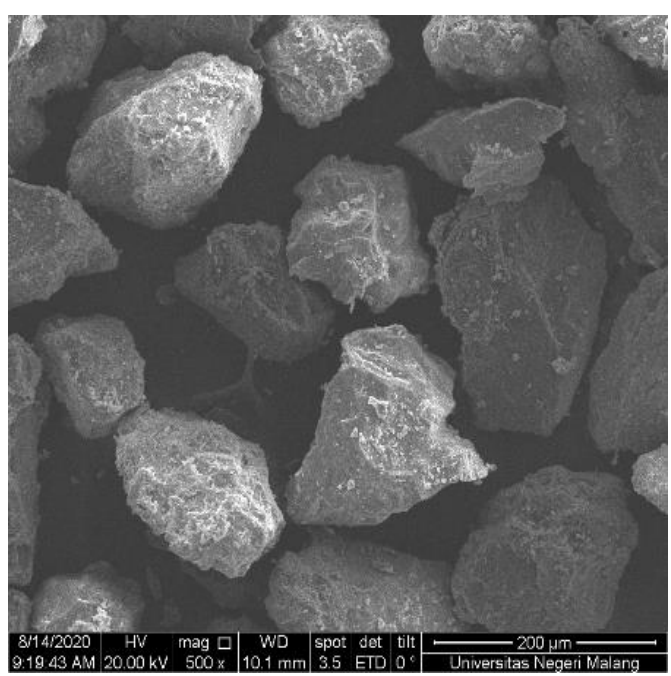

c. Abu letusan 3 Oktober 2018

Gambar 4. Morfologi Partikel Abu Tahun 2016 dan 2018 (Fraksi medium)

Kristalisasi merupakan faktor yang bertanggung jawab bagi terjadinya erupsi eksplosif. Kristalisasi menyebabkan magma bertransformasi dari magma kaya volatil menjadi magma kaya kristal (Kunrat, 2017). Kandungan mikrolit akan melimpah dalam magma akibat pelepasan air dan magma akan bersifat viskoelastik sehingga dapat mencapai kondisi fragmentasi getas untuk berlangsungnya erupsi eksplosif (Moitra et al., 2018). Fragmentasi getas dipicu oleh kristalisasi yang cepat akibat proses pendinginan karena magma bergerak naik dengan cepat ke tingkat yang lebih dangkal (Arzilli et al., 2019). Fragmentasi getas berkaitan dengan bentuk padat dan blok dari abu vulkanik (Hornby et al., 2019). Partikel abu blok bervesikular berkaitan dengan erupsi eksplosif akibat fragmentasi dari magma cair yang mengandung gas (Nurfiani \& de Maisonneuve, 2018).

\section{KESIMPULAN}

Magma Soputan pada erupsi tahun 2016 dan 2018 adalah magma basaltik kaya kristal. Kristalinitas yang tinggi dalam magma berperan penting dalam mengendalikan perilaku eksposifnya. Peningkatan jumlah kristal dalam magma akan meningkatkan viskositas sehingga terbentuk magma yang viskoelastik dan memungkinkan terjadinya fragmentasi getas. Kristalisasi magma pada suatu tingkat dangkal sebelum erupsi 
bertanggung jawab bagi terjadinya erupsi yang sangat eksplosif.

\section{UCAPAN TERIMA KASIH}

Terima kasih kepada Lembaga Penelitian dan Pengabdian Masyarakat Universitas Sam Ratulangi (UNSRAT) yang telah mendanai riset ini melalui skema Riset Dasar Terapan Pemula UNSRAT (RDTPU) 2020.

\section{DAFTAR PUSTAKA}

Arzilli, F., La Spina, G., Burton, M.R., Polacci, M., Le Gall, N., Hartley, M.E., Di Genova, D., Cai, B., Vo, N.T. \& Bamber, E.C. 2019. Magma fragmentation in highly explosive basaltic eruptions induced by rapid crystallization. Nature Geoscience, 12(12): 1023-1028.

Hargreaves, J.S.J. 2016. Some considerations related to the use of the Scherrer equation in powder $\mathrm{X}$-ray diffraction as applied to heterogeneous catalysts. Catalysis, Structure \& Reactivity, 2(14): 33-37.

Hornby, A.J., Lavallée, Y., Kendrick, J.E., Rollinson, G., Butcher, A.R., Clesham, S., Kueppers, U., Cimarelli, C. \& Chigna, G. 2019. Phase partitioning during fragmentation revealed by QEMSCAN Particle Mineralogical Analysis of volcanic ash. Scientific Reports, 9(1): 1-12.

Iacuaniello, M., Montanino, A., De Gregorio, D. \& Zuccaro, G. 2020. Pyroclastic flow mitigation strategies: a new perspective for the red area. Natural Hazards and Earth System Sciences Discussions, 128.

Kunrat, S.L. 2017. Soputan Volcano, Indonesia: Petrological Systematics of Volatiles and Magmas and their Bearing on Explosive Eruptions of a Basalt Volcano.

Moitra, P., Gonnermann, H.M., Houghton, B.F. \& Tiwary, C.S. 2018. Fragmentation and Plinian eruption of crystallizing basaltic magma. Earth and Planetary Science Letters, 500: 97-104.
Namiki, A. \& Manga, M. 2008. Transition between fragmentation and permeable outgassing of low viscosity magmas. Journal of Volcanology and Geothermal Research, 169(1-2): 48-60.

Nurfiani, D. \& de Maisonneuve, C.B. 2018. Furthering the investigation of eruption styles through quantitative shape analyses of volcanic ash particles. Journal of Volcanology and Geothermal Research, 354: 102-114.

Pandara, D.P. 2017. Analisis Tipikal Erupsi Gunung Lokon Periode Erupsi 20122013 Berdasarkan Karakterisasi Mikrostruktur Abu Vulkanik. Jurnal MIPA, 6(2): 36-41.

Pallister, J.S., Bina, F.R., McCausland, W., Carn, S., Haerani, N., Griswold, J. \& Keeler, R. 2012. Recent explosive eruptions and volcano hazards at Soputan volcano-a basalt stratovolcano in north Sulawesi, Indonesia. Bulletin of Volcanology, 74(7): 1581-1609.

Pan, H., Ju, D., Zhao, Y., Wang, Z., Yang, H., Zhang, H. \& Dong, L. 2016. Mechanical properties, hydrophobic properties and thermal stability of the biodegradable poly (butylene adipate-coterephthalate)/maleated thermoplastic starch blown films. Fibers and Polymers, 17(10): 1540-1549.

Tomašek, I., Damby, D.E., Horwell, C.J., Ayris, P.M., Delmelle, P., Ottley, C.J., Cubillas, P., Casas, A.S., Bisig, C. \& Petri-Fink, A. 2019. Assessment of the potential for in-plume sulphur dioxide gas-ash interactions to influence the respiratory toxicity of volcanic ash. Environmental Research, 179: 108798. 